\title{
Trabeculectomy with double low dose of mitomycin C - two years of follow-up
}

This article was published in the following Dove Press journal:

Clinical Ophthalmology

6 December 2011

Number of times this article has been viewed

Donato Errico'

Francesca Scrimieri'

Roberta Riccardi'

Romolo Fedeli'

Giancarlo larossi ${ }^{2}$

'Opthalmology Unit, Glaucoma Service, Azienda Ospedaliera, Cardinale G Panico, Tricase (Le), Italy; ${ }^{2}$ Department of Opthalmology, Ospedale Pediatrico Bambino Gesù, Rome, Italy
Correspondence: Donato Errico

Piazza Cappuccini, 24

73039 Tricase - Lecce, Italy

Tel +390 833773 III

Email donato.errico@tiscali.it
Purpose: To evaluate the efficacy and the safety of a surgical technique in which classic trabeculectomy ab externo is performed with a double application of low-dose mitomycin $\mathrm{C}$ (MMC) in uncontrolled open-angle glaucoma (OAG) patients.

Method: A consecutive series of 43 white patients (43 eyes) with uncontrolled primary OAG underwent trabeculectomy surgery. A double application of MMC $(0.1 \%)$ was performed: the first under the Tenon's capsule for 3 minutes, and the second below the scleral flap for 1 or 2 minutes, according to the risk factors. Complete success was defined as intraocular pressure (IOP) $<14 \mathrm{mmHg}$ without any additional glaucoma surgery or medication. Qualified success was defined as IOP $<14 \mathrm{mmHg}$ with additional needling revision.

Results: Mean preoperative IOP was $29.9 \mathrm{mmHg}$ (SD 3.8) for all eyes evaluated. At 1 day postoperative, mean IOP was $6.7 \mathrm{mmHg}$ (SD 1.26). At the end of the first 2 weeks postoperative, mean IOP was $8.6 \mathrm{mmHg}$ (SD 1.7), at 12 months mean IOP was $11.3 \mathrm{mmHg}$ (SD 1.4; $P<0.0001$ ) and at 24 months mean IOP was $11.4 \mathrm{mmHg}$ (SD 1.5; $P<0.0001$ ). At 3 months, two eyes $(5.4 \%)$ underwent needling of the bleb for cystic blebs formation.

Conclusion: In this study we presented the results after 2 years of follow-up of OAG undergoing trabeculectomy with dual administration of MMC $(0.1 \mathrm{mg} / \mathrm{mL})$. After 24 months, complete success was achieved in $93 \%$ of patients and a qualified success in $100 \%$ of patients.

Keywords: glaucoma, trabeculectomy, mitomycin C

\section{Introduction}

Glaucoma is an ocular disorder characterized by visual field defects and optic nerve head $(\mathrm{ONH})$ damage mainly due to increased intraocular pressure (IOP). Other risk factors such as ocular blood flow, optic disk appearance, and ganglion cell degeneration are involved in the pathogenesis, but to date, lowering the IOP represents the most important clinically significant parameter to prevent the progression of the disease. ${ }^{1,2}$ Indeed, the only accepted treatment for glaucoma is reduction in the IOP, and in many cases, optimal IOP regulation cannot be achieved without surgery.

Trabeculectomy is the gold standard filtrating surgical treatment for medically uncontrolled glaucoma disease since its introduction by Cairns in $1968 .^{3}$ The success of filtrating surgery depends on the healing of the fistula and surrounding tissue, as the fistula can be blocked by a rapidly progressing scar soon after the filtration surgery. Therefore, antiproliferative agents have long been used in conjunction with trabeculectomy in order to inhibit subconjunctival scarring via decreasing fibroblastic activity and modulating wound healing at the bleb site. ${ }^{4}$ 
Mitomycin C (MMC) is one of the most commonly used antiproliferative agents, introduced at the beginning of the 1980s. It is an antineoplastic antibiotic agent isolated from the filtrate fermentation of Streptomyces caespitosus, and has been shown to suppress fibroblastic activity and consequently to inhibit wound healing. ${ }^{5}$ The advantages of its intraoperative use are a reduction of corneal complications, a greater lowering of intraocular pressure, and the elimination of postoperative drugs. ${ }^{6,7}$ However, complications associated with the use of MMC are the formation of thin walled and avascular blebs and extreme hypotony, with or without maculopathy. Toxic effects and complications secondary to use of MMC are strictly dependent on dose and time exposure. ${ }^{8-10}$ The application method of antimetabolite agents during trabeculectomy surgery can affect the drainage bleb morphology and its long-term survival. ${ }^{11}$

Some surgeons prefer to place sponges soaked in antimetabolite on the subconjunctival space or below the Tenon's layer, ${ }^{12,13}$ or to inject antimetabolite into Tenon's layer ${ }^{14}$ prior to scleral flap dissection, while others prefer to place the sponges under the scleral flap itself. ${ }^{15}$

In this article, we describe a technique in which double application of low-dose MMC $(0.1 \mathrm{mg} / \mathrm{mL})$ is performed; the first dose is injected into Tenon's layer and the second is administered by placing a soaked sponge under the dissected scleral flap.

\section{Material and methods}

This is a retrospective case controlled study. The research followed the tenets of the Declaration of Helsinki. The study was approved by the ethics committee of the Cardinal G Panìco Hospital of Tricase.

All the patients were admitted to Cardinal G Panìco Hospital of Tricase for examination at the glaucoma unit. A consecutive series of 43 Caucasian patients (43 eyes), 28 men and 15 women, with uncontrolled open-angle glaucoma (OAG), were recruited for this study between June 2008 and February 2009. Their mean age was 59.5 years (SD 15.7). Of the 43 patients, 25 were pseudophakic and 18 phakic. Pseudophakic patients had been exposed to phacoemulsification with temporal access at least 3 months before trabeculectomy.

Patients were compared with 16 controls who underwent trabeculectomy with a single dose of MMC $0.2 \mathrm{mg} / \mathrm{mL}$ under the scleral flap for 3 minutes in the same period. Controls were seven pseudophakic and nine phakic with mean preoperative IOP of $27.8 \mathrm{mmHg}$ (SD 2.9). The mean age of controls was 62.7 years (SD 16.4).
Patients and controls were defined as having primary OAG (POAG) or secondary glaucoma (pigmentary, exfoliative) if they had an abnormal visual field (as described below), and/or abnormal ONH/retinal nerve fibre layer (RNFL) identified by using a Volk +90 lens (Volk Optical, Inc, Mentor, $\mathrm{OH}$ ), open angle by gonioscopy (Volk 2 in 1 handle gonio-lens (Volk Optical, Inc), and no clinically apparent secondary cause for their glaucoma.

The abnormal ONH and RNFL classifications were based on the presence of an optic rim notch or diffuse/generalized loss of optic rim tissue, vertical cup/disk diameter ratio asymmetry unexplained by side differences in optic disk size, disk hemorrhage, or a localized defect within the RNFL. The visual field testing was assessed with a Humphrey Field Analyzer (HFA, program 24-2, SITA standard, Humphrey Instruments, Munich, Germany). Patients were classified as having an abnormal visual field if on at least three consecutive tests they had a pattern deviation map with at least one of the following defects: (a) three adjacent points depressed by $5 \mathrm{~dB}$ with one of the points down by at least $10 \mathrm{~dB}$; (b) two adjacent points down by $10 \mathrm{~dB}$; (c) a $10 \mathrm{~dB}$ difference across the nasal horizontal meridian in two adjacent points.

None of the points could be edge points except immediately above or below the nasal horizontal meridian. Only reliable fields were used as determined by the reliability parameters (false positive responses and false negative responses $<30 \%$, and fixation losses $<10 \%$ ). ${ }^{16}$

Inclusion criteria were primary or secondary $\mathrm{OAG}$ patients under maximal tolerable antiglaucomatous therapy and with uncontrolled IOP (IOP $>22 \mathrm{mmHg}$ ) and evident signs of deterioration of the visual field recorded in at least two consecutive examinations. ${ }^{16}$

Prior to surgical procedure, all patients underwent a baseline examination including: measurement of best corrected visual acuity; visual field examination (24-2, HFA); biomicroscopy, gonioscopy (Volk 2 in 1 handle gonio-lens, [Volk Optical, Inc], fundus examination (stereoscopic retinal view using Volk +90 diopters lens), and Goldmann applanation tonometry (model AT 900; Goldmann Applanation Tonometer, HaaghStreit-Berne, Mason, $\mathrm{OH}$ ).

Patients' and controls' data are reported in Table 1. Informed consent was obtained from each patient. All surgical procedures were performed by a single surgeon (Donato Errico).

\section{Surgical method}

A standardized surgical technique was used throughout the study period. The surgical procedures were similar in both 
Table I Patient parameters - demography

\begin{tabular}{lll}
\hline Parameter & $\begin{array}{l}\text { Patient } \\
\text { n (\%) }\end{array}$ & $\begin{array}{l}\text { Controls } \\
\text { n (\%) }\end{array}$ \\
\hline $\begin{array}{lll}\text { Sex } \\
\text { Male }\end{array}$ & $28(65 \%)$ & $12(75 \%)$ \\
$\quad \begin{array}{l}\text { Female } \\
\text { Etiology of glaucoma }\end{array}$ & $15(35 \%)$ & $4(25 \%)$ \\
POAG & $22(51 \%)$ & $10(62.5 \%)$ \\
Exfoliative & $19(44 \%)$ & $6(37.5 \%)$ \\
Pigmentary & $2(5 \%)$ & - \\
\hline
\end{tabular}

Abbreviation: POAG, primary open angle glaucoma.

treatment arms. The operation was performed under monitored anesthesia care using a peribulbar block; a 6-0 silk stay suture (B Braun Aesculap, Tuttlingen, Germany) was placed in the superior cornea and the eye inferiorly moved. A 30 gauge needle was passed through the conjunctiva (at $7 \mathrm{~mm}$ from limbus) and it was advanced laterally in Tenon's capsule, creating a bubble (Figure 1); the wound bed was treated with MMC to prevent spread over the future site of the conjunctival wound. The concentration of MMC used was $0.1 \mathrm{mg} / \mathrm{mL}$. After 3 minutes, the perilimbal conjunctiva was opened 5-7 $\mathrm{mm}$ and saline solution was injected into Tenon's capsule. The process was repeated three times, until a total of $10 \mathrm{~mL}$ of balanced saline solution was used. The exposed sclera under the conjunctival flap was cleaned with gentle bipolar diathermy.

A scleral flap $(4 \times 3 \mathrm{~mm})$ was created first by cutting an horizontal incision parallel to the limbus using a precalibrate blade of $250 \mu \mathrm{m}$ (BD, Waltham, MA), then dissecting a partial thickness scleral pocket by crescent knife angled bevel up (Alcon Ophthalmic, Fort Worth, TX), and finally cutting the two side incisions.

A $4 \times 4 \mathrm{~mm}$ piece of sponge soaked in $\mathrm{MMC}(0.1 \mathrm{mg} / \mathrm{mL})$ was placed under the dissected scleral flap (Figure 2).

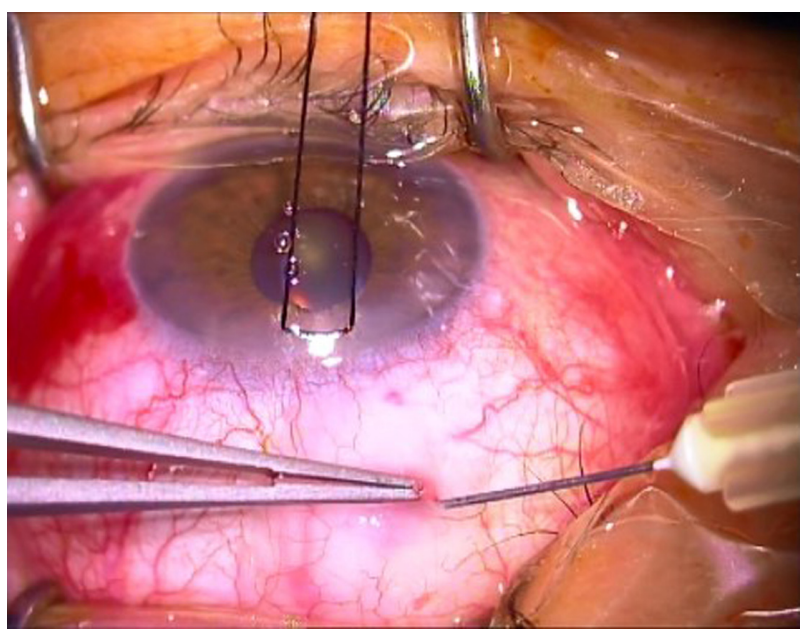

Figure I $0.1 \mathrm{mg} / \mathrm{mL}$ mitomycin bubble inside Tenon's capsule.

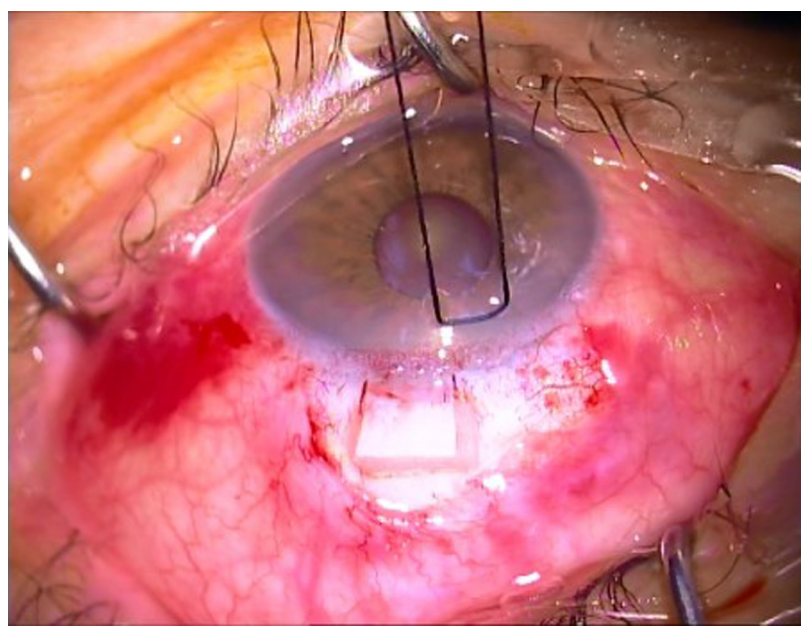

Figure $24 \times 4 \mathrm{~mm}$ piece of sponge soaked in mitomycin $\mathrm{C}(0.1 \mathrm{mg} / \mathrm{mL}$ or $0.2 \mathrm{mg} / \mathrm{mL})$ under dissected scleral flap.

After an exposure time of 1-2 minutes (varied according to the risk factors) the sponge was removed and the area was irrigated with $20 \mathrm{~mL}$ of balanced saline solution. The risk factors taken into account were as follows (Table 2): preoperative IOP, more than 3 years of topical therapy for glaucoma, number of drugs employed, history of argon laser trabeculoplasty (ALT), and age. MMC was applied under the scleral flap for 1 minute in case of two or fewer risk factors ( 23 eyes), and 2 minutes in case of 3 or more risk factors (20 eyes).

A paracentesis was created using a $15^{\circ}$ slit knife (Peasalls Ltd, Taunton, UK), followed by injection of carbacolo solution (Farmigea, Pisa, Italy) and viscoelastic solution (Healon GV Pharmacia, Uppsala, Sweden) in the anterior chamber.

The 2.85-mm blade (Peasalls Limited) was then used to enter the anterior chamber and create sclerotomy. A $1.5-\mathrm{mm}$ diameter hemispherical block of corneal trabecular tissue was excised using a trabeculectomy punch (E Janach, Como, Italy) beneath the scleral flap.

An iridotomy was performed in all cases before the closure of the scleral flap with two 10-0 nylon interrupted sutures (Sharepoint Surgical Specialities Corporation, Reading, PA) (one at each corner, the knots of which were

Table 2 Risk factors for surgery

\begin{tabular}{llc}
\hline & High & Low \\
\hline IOP $(\mathrm{mmHg})^{*}$ & $>30$ & $<30$ \\
Age (years) & $<46$ & $>46$ \\
No of drugs & 3 & $\leq 2$ \\
Time of therapy (years) & $>3$ & $<3$ \\
ALT & + & - \\
\hline
\end{tabular}

Note: *With max tolerable therapy.

Abbreviations: IOP, intraocular pressure; ALT, argon laser trabeculoplasty. 
buried within the sclera), and one releasable suture (centrally on the posterior lip of the flap).

The conjunctiva was closed using 8-0 Safil quick interrupted sutures (B Braun Aesculap, Tuttlingen, Germany) (Figure 3).

Postoperatively, a topical fixed combination of betametasone and chloramphenicol was instilled four times daily for 1 month and cyclopentolate $1 \%$ was instilled two times daily for 2 weeks.

\section{Follow up}

Postoperative data were collected daily during the first week, then at 2 weeks, and later at 1, 3, 6, 12, and 24 months. A routine ophthalmic examination was performed at each follow-up by evaluating visual acuity, IOP, anterior chamber depth, and bleb appearance.

Removal of releasable sutures and digital compression was done within the first 2 weeks as appropriate (sutures are usually removed at 2 weeks postoperative, but can be released earlier if the IOP raises to $19-20 \mathrm{mmHg}$. Needling is only performed in case of Tenonian cyst).

Complete success was defined as IOP $<14 \mathrm{mmHg}$ without any additional glaucoma surgery or medication, whereas qualified success was defined as IOP $<14 \mathrm{mmHg}$ with additional needling revision. We chose a IOP level of $14 \mathrm{mmHg}$ as the target because eyes with IOP less than $14 \mathrm{mmHg}$ are usually believed to be at a safe level of pressure. ${ }^{17}$

For bleb description, the Indiana Bleb Appearance Grading Scale (IBAGS) classification was used. ${ }^{18}$ Statistical analysis was performed using MedCalc $^{\circledR}$ (v 11.3.3.0; MedCalc Software, Mariakerke, Belgium). Conversion of Snellen acuity to the logarithm of the minimum angle of resolution

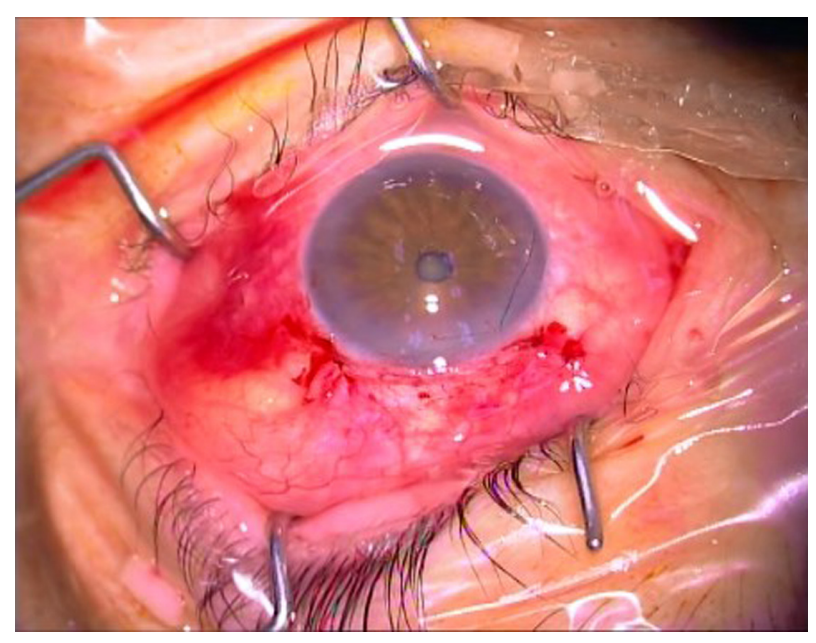

Figure 3 Eye appearance after surgery; releasable suture is visible. values was performed. One-way analysis of variance (ANOVA) was used to calculate the difference in pre-IOP and final IOP, $\Delta \mathrm{IOP}$, and $\Delta$ visual acuity (VA) in patients with different glaucoma diagnoses. $P$ values were calculated using paired sample $t$-tests for preoperative and postoperative values. The one sample $t$-test was used to evaluate the significance of change in each parameter.

\section{Results}

All 43 patients (43 eyes), completed the study. IOP data in patients and controls are reported in Table 3 .

At the end of the first postoperative 2 weeks, mean IOP was $8.6 \mathrm{mmHg}$ (SD 1.7); at 12 months mean IOP was $11.3 \mathrm{mmHg}$ (SD 1.4; $P<0.0001$ ); and at 24 months mean IOP was $11.4 \mathrm{mmHg}$ (SD 1.5; $P<0.0001)$ (Figure 4A).

In controls at 2 weeks mean IOP was $8.9 \mathrm{mmHg}$ (SD 1.9); at 12 months mean IOP was $14.8 \mathrm{mmHg}$ (SD 2.9); and at 24 months mean IOP was $15.5 \mathrm{mmHg}$ (SD 3.2) (Figure 4B).

In the patients group, at 24 months postoperative, the complete success rate, defined as IOP $<14 \mathrm{mmHg}$ without medication was $93 \%$. Qualified success, defined as IOP $<14 \mathrm{mmHg}$ with additional needling revision, was achieved in $100 \%$ of eyes. In the controls group, at 24 months of follow-up, the complete success rate was $67 \%$ and qualified success was achieved with $79 \%$ of eyes.

The bleb in $79 \%$ (34 eyes) of the patients appeared to extend laterally and posteriorly (29 eyes E2, five eyes E1), medium vascularity (V3) without cysts (Figure 5). In $21 \%$ of patients (nine eyes) blebs were less extensive (E 1-2), avascular (V1) with cysts (Figure 6). All blebs were moderately high (H2), no corkscrew vessels were observed (Table 4).

Hypotony was defined as IOP readings of $<7 \mathrm{mmHg}$ obtained on 2 separate days up to 2 weeks postoperative.

The most frequent early postoperative complications during the first 2 weeks after surgery were shallow anterior

Table 3 Intraocular pressure data in patients and controls

\begin{tabular}{lll}
\hline Follow-up & $\begin{array}{l}\text { MMC 0.I two } \\
\text { administrations } \\
\text { IOP mmHg (SD) }\end{array}$ & $\begin{array}{l}\text { MMC 0.2 single } \\
\text { administration } \\
\text { IOP } \mathbf{~ m H g ~ ( S D ) ~}\end{array}$ \\
\hline Preoperative & $29.9(3.8)$ & $27.8(2.9)$ \\
2 weeks & $8.6(1.7)$ & $8.9(1.9)$ \\
I month & $10.2(2.4)$ & $11.1(2.5)$ \\
6 months & $10.9(1.9)$ & $12.4(2.1)$ \\
I year & $11.3(1.4)$ & $14.8(2.9)$ \\
2 years & $11.4(1.5)$ & $15.5(3.2)$ \\
\hline
\end{tabular}

Abbreviations: MMC, mitomycin C; IOP, intraocular pressure. 

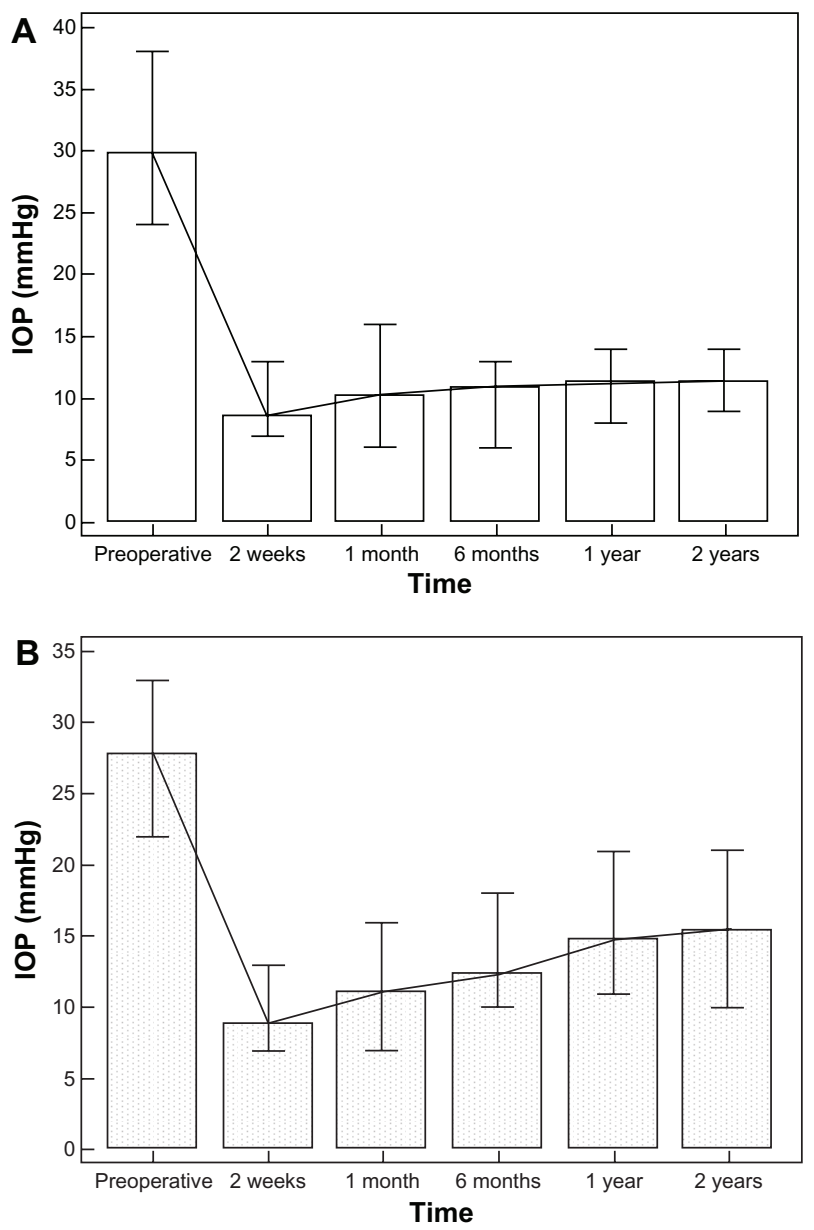

Figure 4 Mean IOP evolution pre- and postoperative: (A) patients (B) controls. Abbreviation: IOP, intraocular pressure.

chamber (ten eyes, 21.7\%, mainly in the first 3 days), hyphema (two eyes, $4.6 \%$ ), and serous choroidal detachments posterior to the equator (five eyes, $11.6 \%$ ). None of the choroidal detachments required surgical drainage nor did phakic patients undergo cataract surgery

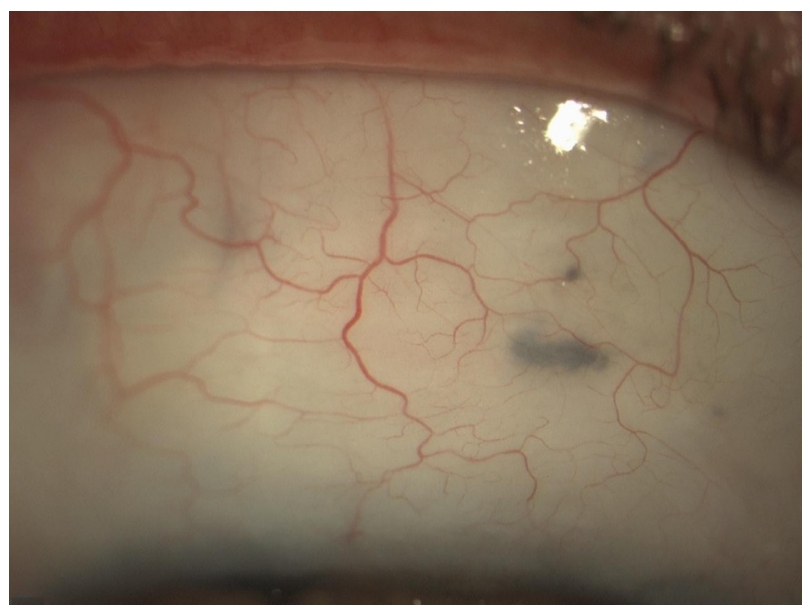

Figure 5 Appearance of bleb without cysts (E2-V3-H2).

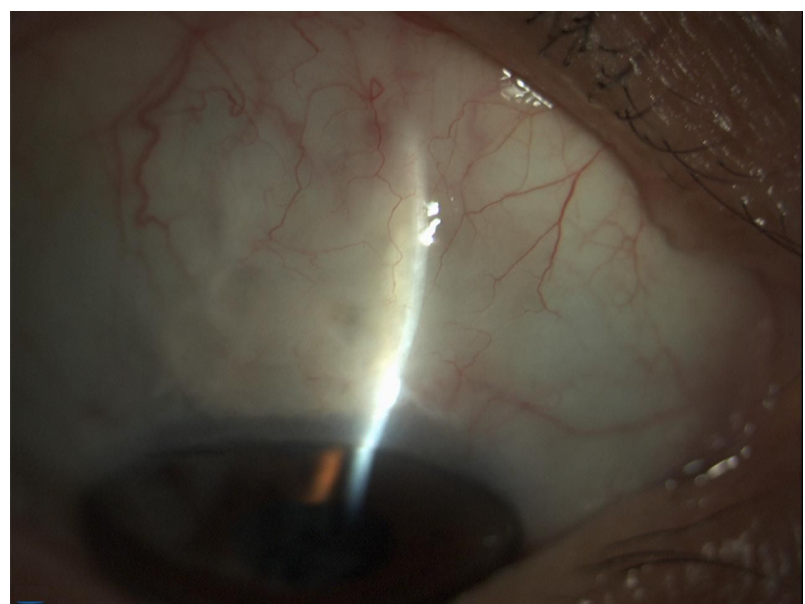

Figure 6 Appearance of bleb with cysts (E2-VI-H2).

during the follow-up period. In all eyes, the releasable sutures were removed during the first 2 weeks of follow-up. At 3 months, three eyes (7\%) underwent needling of the bleb for cystic formation.

Scleral ectasia adjacent to the site of sclerectomy was not observed during the follow-up period of 2 years. Neither persistent nor late bleb leakage nor severe complications, such as bleb infection, endophthalmitis or choroidal hemorrhages, were seen in this series.

Best correct visual acuity did not change after trabeculectomy $(P=0.56)$.

\section{Discussion}

The aim of trabeculectomy surgery is to produce a long-functioning drainage fistula, with minimal risk of complications.

The use of MMC to modulate healing allows lower IOPs to be obtained, but it can cause severe complications such as thin or ischemic blebs, which are associated with leakage and increased risks of endophthalmitis and hypotonous maculopathy. Different application methods of MMC have been proposed to increase its efficiency while decreasing its toxic effects. Various studies have mainly focused on the exposure time of MMC during the surgery and the dosing scheme of the agent. ${ }^{4,9,12-14}$

The inhibitory effects of MMC on subconjunctival fibroblast proliferation in vitro have been shown to be dose and

Table 4 Bleb classification using the Indiana Bleb Appearance Grading Scale $-2003^{18}$

\begin{tabular}{|c|c|c|c|c|c|c|c|c|c|c|c|c|}
\hline & \multicolumn{4}{|c|}{ Height } & \multicolumn{4}{|c|}{ Extent } & \multicolumn{4}{|c|}{ Vascularity } \\
\hline & $\mathbf{I}$ & 2 & 3 & 4 & 0 & $\mathbf{I}$ & 2 & 3 & $\mathbf{I}$ & 2 & 3 & 4 \\
\hline Eyes (n) & & 5 & 38 & & 3 & II & 29 & & 9 & & 34 & \\
\hline
\end{tabular}


time dependent. ${ }^{19}$ Previous authors reported the use of MMC concentration ranging from $0.1 \mathrm{mg} / \mathrm{mL}$ to $0.4 \mathrm{mg} / \mathrm{mL} .{ }^{6,20}$ Chen et $\mathrm{al}^{20}$ reported failure rates of $37.5 \%$ using an $\mathrm{MMC}$ concentration of $0.1 \mathrm{mg} / \mathrm{mL}, 21.9 \%$ using a concentration of $0.2 \mathrm{mg} / \mathrm{mL}$, and no failure using a concentration of $0.4 \mathrm{mg} / \mathrm{mL}$. The success for an IOP target $<21 \mathrm{mmHg}$ was $77.8 \%,(35 / 45$ eyes in high-risk groups). Kitazawa et al in a prospective, randomized study in glaucoma patients with poor surgical prognosis demonstrated that the success rate was $88 \%$ of treated eyes using a dose of the $0.4 \mathrm{mg} / \mathrm{mL}$ MMC.

Lee et $\mathrm{al}^{14}$ injected MMC into Tenon's capsule; MMC concentrations were variable $(0.2-0.5 \mathrm{mg} / \mathrm{mL}$ in accordance with risk factors) and the time of administration was 5 minutes. Ninety-three eyes $(86 \%)$ had an IOP $<21 \mathrm{mmHg}$; 79 (73\%) had an IOP < $16 \mathrm{mmHg}$; and 62 (57\%) had an IOP $<14 \mathrm{mmHg}$ without antiglaucoma medication at 12 months.

Other studies in which MMC has been applied directly to the sclera with MMC-soaked sponges reported high success rates. Beckers et $\mathrm{al}^{21}$ reported a rate of $83 \%$ of patients who achieved an IOP of $15 \mathrm{mmHg}$ or less at 1 year, whereas Fontana et $\mathrm{al}^{22}$ had $84 \%$ of treated patients with an IOP of $15 \mathrm{mmHg}$ or less at 1 year, with an IOP reduction of at least $25 \%$ with respect to preoperative values. In these studies, the concentration of MMC was $0.2 \mathrm{mg} / \mathrm{mL}$ (for 3 minutes) and $0.3 \mathrm{mg} / \mathrm{mL}$ (for 1-3 minutes), respectively.

El Sayyad et $\mathrm{al}^{23}$ compared the results obtained with administration of MMC $0.3 \mathrm{mg} / \mathrm{mL}$ (for 3 minutes) under the conjunctival flap (group 1), scleral flap (group 2), and double application under the scleral flap and conjunctival flap (group 3).

Clinically detectable blebs that were moderately elevated with microcystic conjunctival changes and controlled IOP were noted in 17 of 22 eyes (77\%) in group 1, 15 of 21 eyes (71\%) in group 2, and 18 of 22 eyes (82\%) in group 3 at 1 year after surgery.

Chen et $\mathrm{al}^{20}$ reported hypotony in 16 of 47 eyes. Hypotony of $9 \mathrm{mmHg}$ or less tended to occur more frequently at the higher concentrations of MMC used $(0.2$ and $0.4 \mathrm{mg} / \mathrm{mL})$. Palmer ${ }^{6}$ using $0.2 \mathrm{mg} / \mathrm{mL}$ MMC reported one $(3.8 \%)$ of 26 eyes having hypotony below $5 \mathrm{mmHg}$. These two clinical results reported hypotony rates of $3.8 \%$ using MMC concentrations of $0.2 \% \mathrm{mg} / \mathrm{mL}$ and $66.7 \%$ using a concentration of $0.4 \% \mathrm{mg} / \mathrm{mL}$. The incidence of hypotony after trabeculectomy increased as a function of MMC concentration used during surgery.

When MMC was injected into Tenon's capsula, ${ }^{14}$ hypotony was reported in $21.3 \%$ of cases. At 1 year of follow-up, $19.4 \%$ of patients showed evidence of cystic blebs and $4.6 \%$ had a Tenon's cyst with an IOP $>20 \mathrm{mmHg}$.

El Sayyad et $\mathrm{al}^{23}$ reported intraoperative complications, including conjunctival leaks, in one eye in groups 1 and 2, respectively, compared with two eyes in group 3. One eye in group 3 required conjunctival resuturing. Choroidal effusion, which required choroidal drainage, occurred in one eye in group 1. Hypotony (IOP $\leq 6 \mathrm{mmHg}$ ) was encountered in two eyes in group 1 and in one eye in groups 2 and 3, respectively.

In trabeculectomy, another important element to consider is the extent and appearance of the bleb. Ideally, the bleb should be diffuse and mildly elevated, with normal vascularization. $^{24}$

Önol et al, ${ }^{25}$ in a comparative study, reported major long-term success without increased surgical complication rates for MMC large-area application. The authors compared two groups of OAG patients undergoing trabeculectomy with $\mathrm{MMC}(0.2 \mathrm{mg} / \mathrm{mL}$ for 2 minutes $)$ application with sponges size $4 \times 4 \mathrm{~mm}$ (group 1, smallarea) and $5 \times 5 \mathrm{~mm}$ (group 2, large-area). At the end of the second year, target IOP was achieved in $94.2 \%$ of cases in group 2 and $68.7 \%$ of cases in group $1(P<0.05)$. Mean IOP and additional antiglaucoma medication for the IOP control were less in group 2 than in group $1(P<0.05)$. These findings suggest that large-area MMC application seems to be more advantageous than small-area MMC application in terms of achieving and maintaining target IOP in the long term.

Cordeiro et $\mathrm{al}^{26}$ observed thin and more diffuse blebs with large sponges whereas small and cystic blebs were noted after the use of small sponges. Histopathologic analysis showed a more significant cellular infiltration in small and cystic blebs in comparison with diffuse blebs. They proposed that this cellular infiltration derived from fibroblasts of healthy tissue surrounding the bleb area, and this cellular migration might contribute to the formation of these cystic blebs which were seen in the small-area MMC group.

The area of action of MMC is localized to the area of exposure. Applying the antimetabolites over a wide area is believed to reduce the risk of a cystic bleb forming as well as avoiding increased risks of premature failure caused by scarring around the drainage site. ${ }^{27}$

In this study we presented the results of a 2-year follow-up of OAG patients after trabeculectomy with dual administration of MMC $(0.1 \mathrm{mg} / \mathrm{mL})$. After 24 months, complete success was achieved in $93 \%$ of patients and qualified success in $100 \%$ of patients. 
Our data were consistent with previous studies ${ }^{15}$ where the concentration of MMC was $0.4 \mathrm{mg} / \mathrm{mL}$ and higher, than those obtained with a concentration of $0.1-0.2 \mathrm{mg} / \mathrm{mL}$. By comparing our data with those of group 3 in the El Sayyad ${ }^{23}$ study, we observed a greater success rate $(93 \%$ vs $82 \%)$ and a lower percentage of postoperative complications. A similar success rate $(94.2 \%)$ was achieved by Önol et $\mathrm{al}^{25}$ after administration of MMC with concentration $0.2 \mathrm{mg} / \mathrm{mL}$ for 2 minutes over a large area.

Hypotony in the present study was observed in $4.6 \%$ (two eyes). This percentage is higher than that reported in a previous study ${ }^{6}$ where the MMC at $0.2 \mathrm{mg} / \mathrm{mL}(3.8 \%)$ was administered under conjunctiva before dissection of the scleral flap, but lower than using a $0.4 \mathrm{mg} / \mathrm{mL}$ concentration of MMC (66.7\%). Rate of hypotony was lower to that reported (21.3\%) when MMC was administered intra-Tenon's capsule. ${ }^{14}$ However, in the present study there was no late hypotony. Diffuse filtration was observed in cases with largearea MMC application in the early postoperative period.

At 2 years follow-up, we recorded a 7\% percentage of cystic blebs, significantly lower compared to other studies where cystic bleb percentage was $19.4 \%{ }^{12}$ and $8.8 \%{ }^{25}$ The scleral flap and Tenon's capsule are also involved in the process of fibrosis after trabeculectomy. In accordance with previous reports from Lee ${ }^{14}$ and El Sayyad, ${ }^{23}$ we have standardized the technique of dual administration of MMC $0.1 \mathrm{mg} / \mathrm{mL}$ for 4-5 minutes (varied according to the risk factors). The administration of MMC into Tenon's layer at $7 \mathrm{~mm}$ from the limbus allows the formation of a posteriorly extended and moderately high bleb. The anterior margin of the bubble formed was approximately located at the posterior edge of the scleral flaps. Administration of MMC under the scleral flap permitted the extension of treatment with MMC over a wider area. The two-step administration of single doses of MMC at low percentage $(0.1 \mathrm{mg} / \mathrm{mL})$ covered a large area for a short time (the first for 3 minutes, the second for 1-2 minutes). This prevented the same tissue from coming in contact with the MMC twice. The application of MMC at low doses significantly reduced postoperative complications.

In conclusion, at 24 months after surgery the blebs were widespread, thick-walled, moderately high, and posteriorly extended showing an excellent anatomical and functional outcome after the procedure.

\section{Disclosure}

The authors have no proprietary or commercial interests in any materials discussed in the article. The study was conducted without the support of external grants and the property of the work is exclusively the authors'.

\section{References}

1. Katz LJ, Spaeth GL, Cantor LB, Poryzees EM, Steinmann WC. Reversible optic disk cupping and visual field improvement in adults with glaucoma. Am J Ophthalmol. 1989;107:485-492.

2. O'Brien C, Schwartz B, Takamoto T, Wu DC. Intraocular pressure and the rate of visual field loss in chronic open-angle glaucoma. $\mathrm{Am} \mathrm{J}$ Ophthalmol. 1991;111:491-500.

3. Cairns JE. Trabeculectomy - a preliminary report of a new method. Am J Ophthalmol. 1968;66:673-679.

4. Lama PJ, Fechtner RD. Antifibrotics and wound healing in glaucoma surgery. Surv Ophthalmol. 2003;48:314-346.

5. Singh G, Wilson MR, Foster CS. Mitomycin drops a treatment for pterygium. Ophthalmology.1988;95:813-821.

6. Palmer SS. Mitomycin as adjunct chemotherapy with trabeculectomy. Ophthalmology. 1991;98:317-321.

7. Kitazawa Y, Kawasw K, Matsushita H, Minobe M. Trabeculectomy with mitomycin. A comparative study with fluorouracil. Arch Ophthalmol. 1991;109:1693-1698.

8. Membrey WL, Bunce C, Poinoosawmy DP, Fitzke FW, Hitchings RA. Glaucoma surgery with or without adjunctive antiproliferatives in normal tension glaucoma: 2. Visual field progression. Br J Ophthalmol. 2001;85:696-701.

9. Maquet JA, Dios E, Aragón J, Bailez C, Ussa F, Laguna N. Protocol for mitomycin C use in glaucoma surgery. Acta Ophthalmol Scand. 2005;83:196-200.

10. Jampel HD. Effect of brief exposure to mitomycin $\mathrm{C}$ on viability and proliferation of cultured human Tenon's capsule fibroblast. Ophthalmology. 1992;99:1471-1476.

11. You YA, Gu YS, Fang CT, Ma XQ. Long-term effects of simultaneous subconjunctival and subscleral Mitomycin-C application in repeat trabeculectomy. J Glaucoma. 2002;11:110-118.

12. Skuta GL, Beeson CC, Higginbotham EJ, et al. Intra-operative mitomycin versus postoperative 5Fluorouracil in high-risk glaucoma filtering surgery. Ophthalmology. 1992;99:438-444.

13. Sisto D, Vetrugno M, Trabucco T, Cantatore F, Ruggeri G, Sborgia C. The role of antimetabolites in filtration surgery for neovascular glaucoma: intermediate-term follow-up. Acta Ophthalmol Scand. 2007;85:267-271.

14. Lee E, Doyle E, Jenkins C. Trabeculectomy surgery augmented with intra-Tenon injection of mitomycin C. Acta Ophthalmol. 2008; $86: 866-870$.

15. Beatty S, Potamitis T, Kheterpal S, O’Neill EC. Trabeculectomy augmented with Mitomycin-C application under the scleral flaps. Br J Ophthalmol. 1998;82:397-403.

16. Canadian Ophthalmological Society Glaucoma Clinical Practice Guideline Expert Committee; Canadian Ophthalmological Society. Canadian Ophthalmological Society evidence-based clinical practice guidelines for the management of glaucoma in the adult eye. Can J Ophthalmol. 2009;44 Supp1 1:S7-S93.

17. AGIS Investigators. The Advanced Glaucoma Intervention Study (AGIS): 7. The relationship between control of intraocular pressure and visual field deterioraton. Am J Ophthalmol. 2000;130: 429-440.

18. Cantor LB, Mantravadi A, WuDunn D, et al. Morphologic classification of filtering blebs after glaucoma filtration surgery: the Indiana Bleb Appearance Grading Scale. J Glaucoma. 2003;12(3): 266-271.

19. Yamamoto T, Varani J, Soong HK, Lichter PR. Effects of 5-fluorouracil and mitomycin $\mathrm{C}$ on cultured rabbit subconjuntival fibroblast. Ophthalmology. 1990;97:1204-1210.

20. Chen CW, Huang HT, Bair JS, Lee CC. Trabeculectomy with simultaneous topical application of mitomycin $\mathrm{C}$ in refractory glaucoma. J Ocul Pharmacol. 1990;6:175-182. 
21. Beckers HJ, Kinders KC, Webers CA. Five-year results of trabeculectomy with Mitomycin-C. Graefes Arch Clin Exp Ophthalmol. 2003;241:106-110.

22. Fontana H, Nouri-Mahdavi K, Lumba J, Ralli M, Caprioli J. Trabeculectomy with Mitomycin-C: outcomes and risk factors for failure in phakic open angle glaucoma. Ophthalmology. 2006;113:930-936.

23. El Sayyad F, Belmekki M, Helal M, Khalil M, El-Hamzawey H, Hisham M. Simultaneous subconjunctival and subscleral Mitomycin-C application in trabeculectomy. Ophthalmology. 2000;107:298-302.

24. Jones E, Clarke J, Khaw PT. Recent advances in trabeculectomy technique. Curr Opin Ophthalmol. 2005;16:107-113.
25. Önol M, Aktas Z, Hasanreisoglu B. Enhancement of the success rate in trabeculectomy: large-area mitomycin-C application. Clin Experiment Ophthalmol. 2008;36:316-322.

26. Cordeiro MF, Constable PH, Alexander RA, Bhattacharya SS, Khaw PT. Effect of varying mitomycin-C treatment area in glaucoma filtration surgery in the rabbit. Invest Ophthalmol Vis Sci. 1997;38:1639-1646.

27. Wells AP, Cordeiro MF, Bunce C, Khaw PT. Cystic bleb formation and related complications in limbus-versus fornix-based conjunctival flaps in pediatric and young adult trabeculectomy with Mitomycin-C. Ophthalmology. 2003;110:2192-2197.

\section{Publish your work in this journal}

Clinical Ophthalmology is an international, peer-reviewed journal covering all subspecialties within ophthalmology. Key topics include: Optometry; Visual science; Pharmacology and drug therapy in eye diseases; Basic Sciences; Primary and Secondary eye care; Patient Safety and Quality of Care Improvements. This journal is indexed on

\footnotetext{
Submit your manuscript here: http://www.dovepress.com/clinical-ophthalmology-journal
}

\section{Dovepress}

PubMed Central and CAS, and is the official journal of The Society of Clinical Ophthalmology (SCO). The manuscript management system is completely online and includes a very quick and fair peer-review system, which is all easy to use. Visit http://www.dovepress.com/ testimonials.php to read real quotes from published authors. 